\title{
The Relationship between Multiple Intelligences and the Age of Institutional Teachers \\ Mani Jouzdani ${ }^{1, a}$, Mansoor Tavakkoli ${ }^{1, b}$, Saied Ketabi ${ }^{1, c}$ \\ ${ }^{1}$ Faculty of foreign Languages, University of Isfahan, Isfahan, Iran \\ a mani.jouzdani@yahoo.com, ${ }^{\mathrm{b}} \mathrm{mr}$. tavakoli14@gmail.com , ${ }^{\mathrm{c}}$ ketabi@fgn.ui.ac.ir
}

\begin{abstract}
This study tends to investigate whether the age of English as a Foreign Language (EFL) institutional teachers in Isfahan/Iran have any relationship with the intelligence they prefer to use, whether consciously or unconsciously, in teaching English as a foreign language. The intelligences considered for the purpose of this study are namely Interpersonal and bodily/kinesthetic intelligences proposed by Gardner (1983). In order to conduct this investigation a standardized questionnaire based on Berman (2001) and Christison and Kennedy (1999) Multiple Intelligence (MI) checklist was given to 117 male institutional teachers and the results were calculated using a paired T-test also ten interviews were conducted at the end of the case study on ten teachers after observing their classes. The results suggested that as the age of the teacher increase, to some extent, their preference in using interpersonal intelligence over bodily/kinesthetic intelligence increases as well. Also the case study conducted on one of the institutional teachers proved that teachers of older ages prefer using interpersonal intelligence over bodily/kinesthetic one.
\end{abstract}

\section{Keywords}

multiple intelligence, interpersonal intelligence, bodily/kinesthetic intelligence, age

\section{Academic Discipline And Sub-Disciplines}

Education, Teaching English as a Foreign Language

\section{SUBJECT CLASSIFICATION}

Applied Linguistics

\section{TYPE (METHOD/APPROACH)}

Correlational Method, Questionaire

\section{Council for Innovative Research}

Journal: Journal of Advances in Linguistics

Peer Review Research Publishing System

Vol. 5, No. 2

editorjalonline@gmail.com

www.cirjal.com 


\section{INTRODUCTION}

In 1983 Howard Gardner proposed multiple intelligence theory which focused on the multiplicity of human intelligence as opposed to the theory of IQ which was based on the mono-aspectual perspective of human mind. In this investigation the focus is only on two intelligences Gardner proposed, namely interpersonal intelligence and bodily/kinesthetic intelligence. The reason behind the choosing of these two intelligences is that interpersonal and bodily/kinesthetic intelligences are mostly utilized, over other intelligences, by Iranian institutional teachers regardless of their sex.

What is trying to be achieved in this study is to investigate whether the age of male institutional teachers has any relationship with the intelligence they prefer to use, consciously or unconsciously, meaning that the focus is on determining whether they move from usage of bodily/kinesthetic intelligence toward interpersonal intelligence as they grow older. The aforementioned intelligences are mostly related to the teaching of English as foreign language and also they can be considered to be related to the two prominent methods of language teaching, namely CLT (Communicative Language Teaching) and TPR (Total Physical Response), which are related to interpersonal intelligence and bodily/kinesthetic intelligence respectively.

The results of this investigation can help both teachers and the heads of institutions designing a better curriculum, and choosing better teaching strategies and techniques based on the age of the teachers and their preferred intelligence in language teaching. Gardner's intelligences can be considered to have a significant relationship to both language teaching and learning, many researchers have conducted studies on this relationship, most of which, found a significant relationship between the concepts of $\mathrm{Ml}$ and language teaching and learning. As a complement to the previous studies in present investigation also the factor of age is added.

\section{REVIEW OF LITERATURE}

In a study, Constantinescu (2014), investigated the relationship between teachers' multiple intelligences and the techniques and strategies they use in teaching English. Constantinescu (2014) believed that, each single intelligence that a teacher possessed could affect his or her ways of teaching English. If for example the teacher is logical/mathematically oriented then the teaching of mathematics would be easier for him/her. Based on the results of this study, intrapersonal intelligence helped the teacher to overcome his/her fear and anxiety in stressful situations and speak fluently and effortlessly. Interpersonal intelligence could help the teachers as well through providing them the needed ability to cope with collaborative learning and the situations in which cooperation is demanded. From this investigation it can be inferred that, all intelligences have their own specific role in helping the teacher to become successful in his/her profession. Now the question, and the gap, is that is the age of teachers effective in choosing the proper intelligence for teaching English as a foreign language.

As a proof of importance of multiple intelligences in teaching a foreign language, investigated the effects of multiple intelligence on motivation and work proficiency of school leaders, who were mostly teachers themselves once. The results of the investigation showed that the multiple intelligences had significant effects on the work proficiency and motivation of the teachers and leaders as well. Interpersonal and intrapersonal intelligences along with bodily-kinesthetic and other types of intelligences were proved to be a great source of creativity and inspiration ate work. The results of this study are consistent with the assumptions and hypotheses made in the current investigation to the extent that multiple intelligences have significant effect on the efficiency of teachers and leaders, but the gap which still exists is whether the age of the teachers has any relationship with the type of intelligence they prefer to use whether consciously or unconsciously.

In his paper on perceptions of pre-service teachers on the relationship between multiple intelligence and foreign language learning Savas (2012) endeavored to investigate what intelligences were preferred by these pre-service teachers in language teaching. According to this study linguistic intelligence alone could not guarantee the second language learning success. The results of this study suggested that not only linguistic intelligence but also other intelligences could affect the learning of language. The aim of the present study is to investigate whether there is a relationship between teachers' preferred intelligence and their age, since Savas (2012) in his study suggested that there was a relationship between language and intelligence, so it is possible to assume that there also exists a relationship between age of teachers and their choice of intelligence in language teaching since teachers also must have a certain type of dominant intelligence in language teaching.

In another study Serin, Serin, Yavuz, and Mohammadzade (2009) investigated the relationship between the primary teachers' teaching strategies and their strengths in multiple intelligences sampling in Izmir and Lefkosa. It was suggested that the teaching strengths of teachers in Lefkosa differed from those of the teachers in Izmir. The results of this study suggested that there existed a significant relationship between spatial/visual, naturalistic and interpersonal intelligences and teachers teaching styles and strategies. Since the results suggested that there was significant relationship between $\mathrm{Ml}$ and teaching strategies of teachers so it is possible to assume that there is a relationship between teachers' age and the choice of intelligence preferred by them.

Some of the features of Gardner's multiple intelligence theory are included in a study conducted by Gouws (2008) among which we can focus on the one that assumes multiple intelligences can provide alternatives for human developments regardless of age while it is also mentioned that each and every human being can easily recognize the dominant intelligence (Armstrong, 1994; Gardner, 1983, 1993) According to these assumptions no matter at what age, an individual may still divert from using one intelligence to another. This supports the idea underlying the present study in the sense that as teachers grow older there might be some changes in using their intelligences while teaching English to foreign language students. 


\section{SIGNIFICANCE OF STUDY}

As teachers of second and foreign language grow older sometimes unconsciously they diverse form the previous strategies they used while teaching a language, but the question is why does this happen? Each intelligence, as Gardner (1983) states, is innate and individually specific. But the factor of age can contribute to the usage of each intelligence. With the passage of time the tendency toward using a certain type of intelligence may give place to another type, in this particular study it is assumed that bodily/kinesthetic intelligence gives place to interpersonal intelligence. The results of this study can help teachers to devise the appropriate curriculum based on their age and consequently fulfill their duty as an instructor in the best way possible. Also heads of the institutions may benefit from the results in the sense that they can promote efficiency and performance of the teachers through guiding them in the channel of their preferred intelligence and designing the curriculum according to the age of the teachers.

\section{RESEARCH QUESTION AND HYPOTHESES}

Questions which are to be answered at the end of this investigation are as follows:

1. Is there any relationship between institutional teachers' age and their preferred intelligence?

2. Do teachers prefer interpersonal intelligence over bodily/kinesthetic intelligence as they grow older?

Based on the aforementioned research questions these hypotheses may be formed:

1. There might exist a positive relationship between institutional teachers' age and their preferred intelligence

2. Teacher may prefer interpersonal intelligence over bodily/kinesthetic intelligence as they grow older

\section{METHODOLOGY}

\section{Participants}

For the purpose of this investigation 117 male institutional teachers from various institutions across Isfahan/Iran were selected. The age of the teachers varied from 20 to 60 with academic degrees ranged from M.A to PhD and they all had advanced level of English proficiency. The teachers were non-native speakers and did not use English as second language outside of classroom.

\section{Instruments}

For the purpose of this investigation a questionnaire consisting of two parts, one related to bodily-kinesthetic intelligence and the other related to interpersonal intelligence was utilized in order to investigate both intelligences and compare them to determine the preferred one. The questionnaire used in this investigation was based on Berman (2001) and Christison and Kennedy (1999) Ml checklist. The reliability and validity of these two questionnaires were predetermined by Berman (2001) and Christison and Kennedy (1999) and proved to be reliable and valid. Also at the end of the case study conducted after the questionnaires were gathered, ten teachers were interviewed and observed in order to increase the validity of the results.

\section{Procedure}

A number of questionnaires were given to each institution according to the number of the teachers. The teachers were part time employees and most of them had to take the questionnaires with them to home. After 3 weeks these questionnaires were gathered to be scored and analyzed. According to heads of some of the institutions a few teachers filled the questionnaire at the presence of the head of institution, in order to prevent any fluctuations in the results of the study these participants were excluded from the investigation. After the questionnaires were collected, ten teachers were selected randomly for observation and interview. The teachers were observed for four sessions and at the end of the fourth session they were interviewed in order to increase the validity of the results produced through the questionnaire.

\section{RESULTS AND DISCUSSION}

To investigate the aforementioned hypotheses, 117 participants from 11 institutions were randomly selected and presented with Berman (2001) and Christison and Kennedy (1999) standardized MI Checklists. 3 of the 117 participants filled the questionnaires in the presence of head of the institution. Therefore, the results for these 3 participants could be falsified due to Hawthorne effect especially for young teachers. In addition, the falsification may also be caused by Halo effect for the presence of the head of the institution. Hence, these 3 participants were excluded from the data set. In addition, 2 of the participants were not willing to mention their age and/or their years of teaching experience so they were also excluded.

After some experiments with scatter plots, linear regression analyses were utilized to investigate the relationship between interpersonal and bodily/kinesthetic intelligences of the 112 remaining participants using Minitab® 16.0.0. The following Table (i.e. Table 1) presents a summary of the linear regression models.

From the models, it can be inferred that there is a very weak relationship between the variables. Furthermore, some of the coefficients are not even statistically significant. As depicted in the following Table (i.e. Table 2), the p-values for some of the coefficients show that there is no statistically significant relationship between some of the variables. 
Table 1.The linear regression models

\begin{tabular}{|l|l|l|}
\hline \multicolumn{1}{|c|}{ Independent Vars. } & Interpersonal intelligence & bodily/kinesthetic intelligence \\
\hline Dependent Vars. & $\begin{array}{l}\text { Interpersonal Intel. Score }= \\
43.485-0.00218033 \text { Age } \\
\text { R-Sq. }=0.00 \%\end{array}$ & $\begin{array}{l}\text { Bodily/Kinesthetic Intel. Score } \\
43.3148-0.133187 \text { Age } \\
\text { R-Sq. }=9.76 \%\end{array}$ \\
\hline Years of Experience & $\begin{array}{l}\text { Interpersonal Intel. Score } \\
44.1478-0.106276 \text { Experience } \\
\end{array}$ & $\begin{array}{l}\text { Bodily/Kinesthetic Intel. Score }= \\
40.6419-0.150077 \text { Experience } \\
\text { R-Sq. }=7.59 \%\end{array}$ \\
\hline
\end{tabular}

Table 2. The statistical significance of the linear regression models

\begin{tabular}{|c|c|c|c|c|c|c|}
\hline Independent Vars. & \multicolumn{3}{|c|}{ Interpersonal intelligence } & \multicolumn{3}{|c|}{ bodily/kinesthetic intelligence } \\
\hline \multirow[t]{3}{*}{ Age } & Term & Coefficient & P-Value & Term & Coefficient & P-Value \\
\hline & Constant & 43.485 & 0.000 & Constant & 43.3148 & 0.000 \\
\hline & Age & -0.0022 & 0.974 & Age & -0.1332 & 0.099 \\
\hline \multirow[t]{3}{*}{ Years of Experience } & Term & Coefficient & P-Value & Term & Coefficient & P-Value \\
\hline & Constant & 44.1478 & 0.000 & Constant & 40.6419 & 0.000 \\
\hline & Experience & -0.1063 & 0.156 & Experience & -0.1501 & 0.163 \\
\hline
\end{tabular}

More specifically, interpersonal intelligence does not significantly change with age and years of experience of the teacher. A similar conclusion is drawn for bodily/kinesthetic intelligence versus years of experience. However, the situation is slightly different for the relationship between bodily/kinesthetic intelligence and age of the teacher; i.e., at $\alpha=0.1$ confidence level, the coefficient of age variable in the regression model is significant. However, the changes in the age variable explain only $9.76 \%$ of the changes in bodily/kinesthetic intelligence as the dependent variable. Therefore, it can be inferred that age of the teacher along with some other unknown factors explain the changes in bodily/kinesthetic intelligence of the teachers.

Also after observing ten teachers who were chosen randomly for the interview, it was obvious that according to their ages (nearly 50 years old), they preferred using interpersonal intelligence over bodily/kinesthetic intelligence. Especially in teaching new vocabularies and the parts of the book which needed movement and using body gestures, they preferred to explain the meanings and definitions or show a picture instead of acting out the meaning of the new word. During the interview the teachers stated that they used to move around the class and act out the meaning and definition of all words but now they feel better when they use AVA such as pictures and clips. They also stated that talking and conversing with other students has always been one of their favorite strategies to get to their point and let students find out the meanings and definitions themselves. It can be concluded that they prefer using interpersonal intelligence through conversing with students.

From the statistics and the interviews it can be inferred that first hypothesis which assumed that "There might exist a positive relationship between institutional teachers' age and their preferred intelligence" can be partially accepted since the relationship between interpersonal intelligence, age and years of experience is proven to be weak statistically. As for the second hypothesis "Teacher may prefer interpersonal intelligence over bodily/kinesthetic intelligence as they grow older", it can be concluded that since age of the teacher cause changes in the usage of bodily/kinesthetic intelligence over time then it can be inferred that as teachers grow older their tendency towards bodily/kinesthetic intelligence weakens. Also the results of the interviews prove that 50 year old teachers prefer interpersonal intelligence and the teaching strategies related to it compared to bodily/kinesthetic intelligence and its strategies.

It is advisable that further research and investigation be conducted on the preferred intelligence among the female language teachers of different ages since the population and the sample selected for this investigation were male institutional teachers. Also the relationship between age and preferred intelligence of university professors can be investigated, especially, for those in the field of teaching English as a foreign/second language.

\section{RESFERENCE}

[1] Armstrong, T. (1994). Multiple Intelligences in the classroom: Alexandria: ASCD.

[2] Berman, Michael. (2001). ELT through multiple intelligences: London: NetLearn Publications.

[3] Christison, Mary Ann, \& Kennedy, Deborah. (1999). Multiple intelligences: Theory and practice in adult ESL: ERIC Clearinghouse. 
[4] Constantinescu, Roxana Sorina. (2014). The Theory of Multiple Intelligences- Applications in Mentoring Beginning Teachers. Procedia, 3345-3349.

[5] Gardner, H. (1983). Frames of Mind: The Theory of Multiple Intelligences

[6] Gardner, H. (1993). Multiple Intelligences: The Theory and Practice. New York: Basic Books.

[7] Gouws, F.E. (2008). Teaching and learning through multiple intelligences in the outcome-based education classroom. African Education Review, 60-75.

[8] Savas, Perihan. (2012). Pre-service English as a foreign language teachers' perceptions of the relationship between multiple intelligences and foreign language learning. Learning and Individual Differences, 22(6), 850855.

[9] Serin, Nerguz Bulut, Serin, Oguz, Yavuz, M. Ali, \& Mohammadzade, Behbud. (2009). The relationship between the primary teachers' teaching strategies and their strenghts in multiple intelligences. Procedia, 1, 708-712.

\section{Authors' Biography}

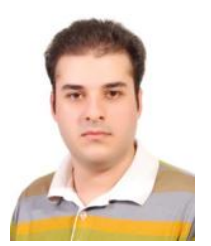

Mani Jouzdani was born in Isfahan, Iran on $3^{\text {rd }}$ of November, 1989. He got his B.A degree in English literature from the University of Urmia in 2012. He is going to get his M.A degree in Applied Linguistics from the University of Isfahan in January, 2015.

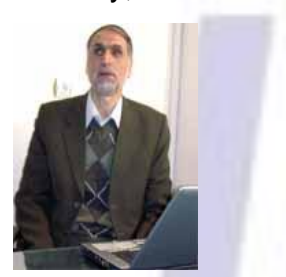

Dr. Mansoor Tavakkoli is an assistant professor in faculty of foreign languages in university of Isfahan. He has published several papers in different international journals including International Journal of Research Studies in Educational Technology, World Applied Sciences Journal, and Journal of Language Teaching and Research.

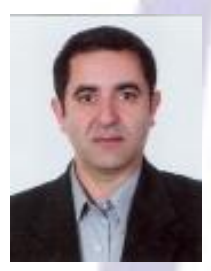

Dr. Saeed Ketabi is an associate professor in faculty of foreign languages in university of Isfahan. He has published several papers in different international journals including The Iranian EFL Journal, Reading Psychology, and International Journal of Advanced Studies in Humanities and Social Science. 